\title{
Improvement of the Silicon Solar Cell Performance by Integration of an Electric Field Source in the Solar Cell or Solar Module System
}

\author{
Adama Ouedraogo ${ }^{1,2 *}$, Serge Dimitri Y. B. Bazyomo², Salifou Ouedraogo², Abdoul Razakou1, \\ Dieudonné Joseph Bathiebo \\ ${ }^{1}$ National Authority for Radiation Protection and Nuclear Safety, Ministry of Environment of Burkina Faso, Ouagadougou, \\ Burkina Faso \\ ${ }^{2}$ Laboratory of Thermal and Renewable Energies, Department of Physics, Unit of Training and Research in Pure and Applied \\ Sciences, University of Ouaga 1 Prof. Joseph KI-ZERBO, Ouagadougou, Burkina Faso \\ Email:*damissau@hotmail.com
}

How to cite this paper: Ouedraogo, A., Bazyomo, S.D.Y.B., Ouedraogo, S., Razakou, A. and Bathiebo, D.J. (2018) Improvement of the Silicon Solar Cell Performance by Integration of an Electric Field Source in the Solar Cell or Solar Module System. Smart Grid and Renewable Energy, 9, 285-298.

https://doi.org/10.4236/sgre.2018.912018

Received: November 23, 2018

Accepted: December 25, 2018

Published: December 29, 2018

Copyright (c) 2018 by authors and Scientific Research Publishing Inc. This work is licensed under the Creative Commons Attribution International License (CC BY 4.0).

http://creativecommons.org/licenses/by/4.0/

\section{c) (i) Open Access}

\begin{abstract}
This manuscript is about a theoretical modelling of conversion efficiency improvement of a typical polycrystalline Si solar cell in $1 \mathrm{D}$ assumptions. The improvement is brought by the increase of the collection of the minority carriers charge in excess. This increase is the consequence of the influence of an electric field provided by the use of the open circuit photovoltage of another silicon solar cell. We assume that it is integrated two silicon solar cells to the system. The first solar cell provides the open circuit photovoltage which is connected to two aluminum planar armatures creating a planar capacitor. The second solar cell is placed under the uniform electric field created between the two aluminum armatures. This work has shown an improvement of the output electric power leading to the increase of the conversion efficiency. We observe an increase of $0.7 \%$ of the conversion efficiency of the second silicon solar cell.
\end{abstract}

\section{Keywords}

Open Circuit Photovoltage, Planar Capacitor, Electric Field, Conversion Efficiency, Monochromatic Illumination and Silicon Solar Cell

\section{Introduction}

The photovoltaic energy presents more opportunities to energy access by its easy implementation. Since the first solar cell presented by Bell Laboratory in 1954 [1], the solar cell has known a lot of improvements. After, the conventional 
solar cell, in 1970 it has been added the back surface field (BSF) [2]. The addition of the BSF has led to the improvement of the conversion efficiency. The market of the solar cell is dominated by the use of the silicon because of the low cost and easy accessibility of this semiconductor. But the laboratories data show that the photovoltaic silicon solar cell efficiency is around 26\% [3] [4] today. However, the energy demand is very high and very urgent particularly in the developing countries as Burkina Faso. In fact, Burkina Faso has an energy deficit more than $50 \mathrm{MW}$ with just $19 \%$ as national electricity coverage rate according to the national electricity society called SONABEL. To solve these problems, the energy sources such as photovoltaic solar energy are an alternative. The country faces a proliferation of solar photovoltaic installations in both urban and rural areas and so often in different environments hard conditions. There is very high temperature (more than $40^{\circ} \mathrm{C}$ in April) in Sahel region, strong solar irradiation, an important dust coverage and the electric and/or magnetic field sources often in vicinity of the photovoltaic installations. In fact, the fill factor and hence the efficiency of the silicon solar cell is decreasing with the increase of the temperature [5]. The solar cell electric parameters are presenting an improvement when the solar illumination is increasing [6] [7]. Moreover, the dust contributes to reduce the performance of the photovoltaic solar installations by coverage of the enlightened zone of the solar cell. The electromagnetic field provides more kinetic energy to the minority carriers charge in excess which cross importantly the junction of the solar cell. That causes a deterioration of the quality of the solar cell [8] [9] [10]. The magnetic field is reducing the solar cell performances [11]. The electric field, according to a best orientation, is presenting an improvement of these performances [12] [13] [14] if a monocrystalline silicon solar cell is submitted to an external strong electric field. This submission is causing the decrease of the open circuit photovoltage. This decrease is caused by the surface and the volume recombination and by the ionization which is the strong electric field effect [14]. But this experimental study does not seem to prove the presence of the conduction current demonstrated by Ouedraogo et al. [9] which is engendered by the electric field. The decrease of the open circuit photovoltage is the effect of an important crossing of the junction of the solar cell by the minority charge in excess as shown by Zoungrana et al. (2012) [12] and not by the surface and volume recombination following Erel et al. (2006) [14]. Then, the energy provided by the electric field is lower than $12 \mathrm{eV}$, so it can not cause the ionization of the semiconductor of silicon [15]. On the other hand, a study had been conducted on amorphous, polycrystalline and monocrystalline silicon solar cells submitted to an external electric field under a tungsten filament lamp illumination. For these different silicon solar cells, the electric power is increasing [13]. But all of these studies use an external source such as an electrical grid or an electric battery to generate the electric field. It is so technically difficult to get the improvements of the electric power for a large photovoltaic installation. This is not the case with our system that generates the electric field independently of an external source. The specificity of the present study concerns the integration 
of the source of generation of the electric field in the photovoltaic device. This integration can reduce the amount of material used. We propose in the present paper, a planar capacitor created to integrate the production source of the electric field in the solar cell or solar module system. This integration of the electric field source in the solar cell can bring the increase of the conversion efficiency and can reduce the use of the semiconductor mater's quantity. One-dimension (1D) approach (following only $\mathrm{x}$ axe photogeneration of the minority carriers in excess) is used to develop theoretically the modelling of this integration and to observe the behavior of the photocurrent, the photovoltage, the electric power and the conversion efficiency. For the next, the first section will give the methods and the different theories. The second section will present the results and the discussion. The last section of this work will provide the conclusion of the effect of this integration of the electrical source on the second solar cell performances.

\section{Theory}

\subsection{Creation of the Electrical Field}

The electric field is created using the planar capacitor principle. Two aluminum conductors are used to be connected to the first silicon solar cells as presented on the Figure 1.

The both aluminum conductors connected to the first solar cells become the cathode and the anode of the planar capacitor. When the external solar cells are illuminated, they give the open circuit photovoltage expressed by the Equation (1) [16].

$$
V_{C O}=\lim _{S_{f} \rightarrow 0} V_{p h}\left(S_{f}\right)
$$

where $V_{p h}\left(S_{f}\right)$ in Volt $(\mathrm{V})$ depending of the junction dynamic velocity $\left(S_{f}\right)$ in $\mathrm{cm} \cdot \mathrm{s}^{-1}$, is the photovoltage given by the first solar cells. $S_{f}$ will be defined in the next. By this open circuit photovoltage, the electric field is created in the vacuum (air) presents between both aluminum conductors. The first solar cells are kept only in open circuit state. It has not contribution in the photocurrent and photovoltage of the final system. The main role of the fist solar cells is to provide the electrical field. The expression of this electric field is:

$$
E(d, n)=\frac{n \times V_{C O}}{d}
$$

where $d(\mathrm{~cm})$ is the distance between the both aluminum conductors, $n$ the numbers of the solar cells used to create the electric field and $E(d, n)$ in V.m ${ }^{-1}$ the electrical field depending of the distance $d(\mathrm{~cm})$, of the number of the solar cells and of the different intrinsic parameters of the solar cell. The Figure 2 illustrates a schematic representation of the installation of the silicon solar cells under the uniform electrical field created between the both aluminum conductors.

The silicon solar cells are influenced by the uniform electrical field which is generated between the both aluminum conductors. That causes the apparition of the conduction current. The orientations of the solar cells between the two 


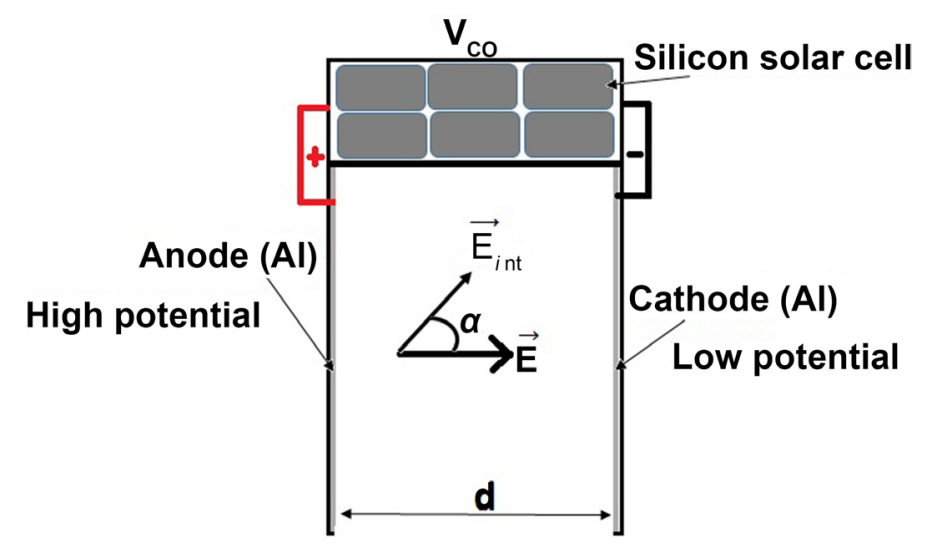

Figure 1. Integration of the electrical field production source into solar cell or solar module.

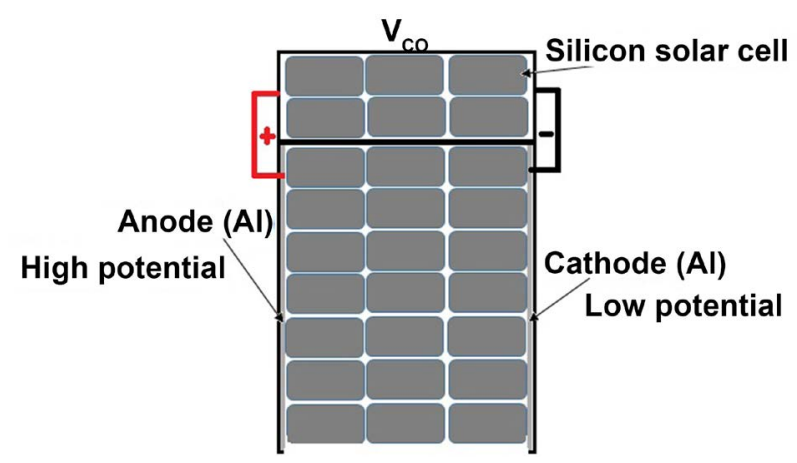

Figure 2. Installation of solar cells under uniform electrical field.

aluminum conductors is chosen for the kind where the internal electric field between $\mathrm{p}-\mathrm{n}$ junction and external electrical field will give a resulting component. This assumption is based on the study developed by Zerbo et al. [10] about electromagnetic field. One solar cell will be placed between the two aluminum conductors for one solar cell chosen for the creation of the external electric field. To solve the illumination problem of the solar cell and to avoid the perpendicularity between internal electrical field of the space charge region and external electrical field created, the height of the anode will be greater than the height of the cathode. It will be added a tilt of the solar cell between anode and cathode. These all means will put an angle between the both electrical fields. The variation of this angle allows to choose a better position giving an optimum output of the second solar cell. Some other work will study the real quantity of external electrical field which will influence the second solar cell. In the present work it will be assumed that the external electrical field which will be provided to the solar cells between anode and cathode will be optimum. The following subsection is going to provide the calculations of the density of the photocurrent, the photovoltage and the electric power.

\subsection{Establishment and the Resolution of the Continuity Equation}

The electric parameters of the silicon solar cell installed between the both alu- 
minum conductors are obtained by solving of the transport equation of the exceeding minority carriers. It is given by the Equation (3) [17]

$$
\boldsymbol{J}_{n}=e D_{n} \cdot \boldsymbol{g r a d} \delta(x)+e \cdot \mu_{n} \cdot \boldsymbol{E} \delta(x)
$$

$D_{n}\left(\mathrm{~cm} \cdot \mathrm{s}^{-2}\right)$ is the electron diffusion coefficient, $\mu_{n}\left(\mathrm{~cm}^{2} \cdot \mathrm{V}^{-1} \cdot \mathrm{s}^{-1}\right)$ is the electron mobility coefficient caused by the electrical field $\boldsymbol{E}, e$ is the electronic charge and $\delta(x)$ in $\mathrm{cm}^{-3}$ which is the density of the exceeding minority carriers charge. This equation is solved in $1 \mathrm{D}$ approach. The assumptions of the $1 \mathrm{D}$ theory are described by Zerbo et al. [18], Zerbo et al. (2014) [8] and Zoungrana et al. (2012) [12]. The resolution of this equation allows to find the different components of the Equation (3) [8] [18]. The equation 3 leads to the calculation of the equation of conservation of exceeding minority carriers charge called continuity equation presented in the Equation (4) [7]. This equation is calculated for the structure of the polycrystalline silicon solar cell considered as $n^{+}-p-p^{+}$ [8].

$$
\frac{\partial \delta(x)}{\partial t}=\frac{1}{e} \operatorname{div}\left(\boldsymbol{J}_{n}\right)+G_{n}(x)-R_{n}(x)
$$

With $G_{n}(x)$ in carriers $\cdot \mathrm{s}^{-1} \cdot \mathrm{cm}^{-3}$ giving the exceeding minority carriers charge generation rate. To analyze the influence of the different light, this study will be done under the monochromatic illumination. $R_{n}(x)$ in carriers $\cdot \mathrm{s}^{-1} \cdot \mathrm{cm}^{-3}$ is the exceeding minority carriers charge recombination rate after the generation.

$G_{n}(x)-R_{n}(x)$ provides the quantity of the exceeding minority carriers charge which are conserved during the cross of the solar cell junction without being recombined [7]. The expression of the recombination rate is given by $R_{n}(x)=\frac{\delta(x)}{\tau}$ [19].

This study is led under monochromatic illumination because this illumination allows to evaluate the effect of any light wavelength where photovoltaic conversion takes place only between $0.4 \mu \mathrm{m}-1.1 \mu \mathrm{m}$. The expression of $G_{n}(x)$ for monochromatic illumination is given by Mathieu H. [7] and Moliton A. [6].

$$
G_{n}(x)=\alpha(\lambda) \phi_{0}[1-\rho(\lambda)] \mathrm{e}^{-\alpha(\lambda) x}
$$

$\alpha(\lambda)$ and $\rho(\lambda)$ are respectively absorption and reflection coefficient at the wavelength $\lambda(\mu \mathrm{m})$ and $\phi_{0}\left(\mathrm{~W} \cdot \mathrm{m}^{-2}\right)$ is the incident photon flux. The monochromatic illumination parameters are provided by Green M. A. (2008) [20]. This work is realized in steady state conditions, the carriers charge density is not function of the time. Then, $\frac{\partial \delta(x)}{\partial t}=0$. Defining $\delta(x)$ as the exceeding minority carriers charge at $x$ position which across the $p-n^{+}$junction of the solar cell, the relevant differential equation is simple.

$$
\frac{\partial^{2} \delta(x)}{\partial x^{2}}+\frac{\mu_{n} E}{D_{n}} \frac{\partial \delta(x)}{\partial x}-\frac{\delta(x)}{L_{n}^{2}}=-\frac{G_{n}(x)}{D_{n}}
$$


With $L_{n}$ the minority carrier length. The solution of Equation (6) is the sum of two members as shown by the Equation (7)

$$
\delta(x)=\delta_{O}(x)+\delta_{I}(x)
$$

where $\delta_{O}(x)$ is the density of minority carriers charge in excess for a solar cell at obscurity because it is calculated without illumination and its expression is $\delta_{O}(x)=\mathrm{e}^{\beta x}[A \cosh (\gamma x)+B \sinh (\gamma x)]$. With $\mathrm{A}$ and $\mathrm{B}$ are found by the solar cell boundaries conditions given by Zerbo et al. $(2011,2014)$ [8] [18]:

- At the solar cell p-n junction

$$
\left.D_{n} \frac{\partial \delta(x)}{\partial x}\right|_{x=0}=S_{f} \delta(0)
$$

- At the rear face

$$
\left.D_{n} \frac{\partial \delta(x)}{\partial x}\right|_{x=H}=-S_{b} \delta(H)
$$

where $S_{b}$ provides the rear face recombination velocity. $S_{f}$ gives the expression of the junction dynamic velocity. It is the sum of two contributions: $S_{f_{0}}$ which is the intrinsic junction recombination velocity related to the losses of carriers at the junction interface and $S_{f_{j}}$ which is the junction dynamic velocity imposed by an external load resistance and defining the operating point of the cell [21] [22] [23], therefore $S_{f}=S_{f_{0}}+S_{f_{j}}$. To carry out this study, the ideal case will be assumed. Hence, $S_{f_{0}}=0$.

The second member of the Equation (7) is the contribution under solar illumination. Its expression is

$\delta_{I}(x)=k \mathrm{e}^{-\alpha(\lambda) x}$ with $k=-\frac{\alpha(\lambda) \phi_{0}[1-R(\lambda)] L_{n}^{2}}{D_{n}\left[\alpha^{2}(\lambda) L_{n}^{2}-1\right]}$. The density of the carrier's minority in excess will be depending of the $S_{f}, S_{b}, \lambda, x, d$ and the other intrinsic parameters of the silicon semi-conductor. The calculation of the exceeding minority carrier charge allows to find the electrical parameters. These electric parameters of the solar cells are presented in the next subsection.

\subsection{Electrical Parameters for a Solar Cell under Electrical Field}

The first electrical parameter of the silicon solar cell is the density of photocurrent. By application of the Fick law, it is expressed as [8]:

$$
J_{p h}\left(S_{f}, S_{b}, \lambda, d\right)=e\left[\left.D_{n} \frac{\partial \delta\left(x, S_{f}, S_{b}, \lambda, d\right)}{\partial x}\right|_{x=0}+\mu_{n} \cdot E \cdot \delta\left(0, S_{f}, S_{b}, \lambda, d\right)\right]
$$

The second electric parameter is the photovoltage which is expressed in Equation (11) by application of the Boltzmann law [8].

$$
V_{p h}\left(S_{f}, S_{b}, \lambda, d\right)=V_{T} \ln \left(\frac{\delta\left(0, S_{f}, S_{b}, \lambda, d\right)}{n_{0}}+1\right)
$$


where $V_{T}$ is the thermal photovoltage. At $T=300 \mathrm{~K}, V_{T}=0.026 \mathrm{~V}, n_{0}=\frac{N_{B}}{n_{i}^{2}}$ with $N_{B}=10^{17} \mathrm{~cm}^{-3}$, the doping level and $n_{i}=1.45 \times 10^{10} \mathrm{~cm}^{-3}$, the intrinsic carriers' density at thermal equilibrium. This subsection will finish by the electric power which is the arithmetical multiplication between the density of photocurrent and the photovoltage.

$$
P_{p h}\left(S_{f}, S_{b}, \lambda, d\right)=V_{p h}\left(S_{f}, S_{b}, \lambda, d\right) \times J_{p h}\left(S_{f}, S_{b}, \lambda, d\right)
$$

The maximum electric power is found by using the curves of the electric power in function of the junction dynamic velocity obtained with Mathcad 15 software. The conversion efficiency is the ratio of the maximum electric power $\left(P_{M P P}\left(\mathrm{~W} \cdot \mathrm{m}^{-2}\right)\right)$ by the incident power $\left(P_{a b}\left(\mathrm{~W} \cdot \mathrm{m}^{-2}\right)\right)$ from solar illumination absorbed in the base of the solar cell. The conversion efficiency for monochromatic is expressed by the Equation (13) [7]

$$
\eta=\frac{P_{M P P}}{P_{a b}}
$$

With $P_{a b}=\frac{\alpha(\lambda) \phi_{0}[1-R(\lambda)] h c}{\lambda}$ where $h=6.632 \times 10^{-34} \mathrm{~J} \cdot \mathrm{s}$ is the Planck constant and $c=3 \times 10^{10} \mathrm{~cm} \cdot \mathrm{s}^{-1}$ is the vacuum light speed. The next section will be concerned to the results and discussions of this work.

\section{Results and Discussion}

\subsection{Evolution of the Electrical Field Created between Both Conductors}

The electrical field created between the both aluminum conductors is depending of solar wavelength, the distance between the cathode and the anode, the number of the silicon solar cells which are using to create the open circuit voltage and the intrinsic parameters of the solar cell. The Figure 3 presents the behavior of the electrical field in function of the number of the silicon solar cells.

The electrical field increases for the increase of the solar cells number. In fact, the increase of the solar cells number causes the increase of the open circuit photovoltage. One of the purposes of this work is to provide an improvement of the conversion efficiency by reducing of the silicon matter. Consequently, the creation of the electrical field must use less solar cells reducing the semiconductor matter used for the manufacture of the solar cells. The Figure 4 gives the evolution of the electrical field in function of the distance between the both aluminum conductors.

The electrical field is very strong for the short distances and it is weak for the greater distances between anode and cathode of the planar capacitor. The physics signification is that the short distances are causing higher electrical field. So, it will be better to have short distance between the aluminum conductors in order to obtain higher electrical field. The evolution of the electric field in function of the solar illumination wavelengths is given by the Figure 5 . 


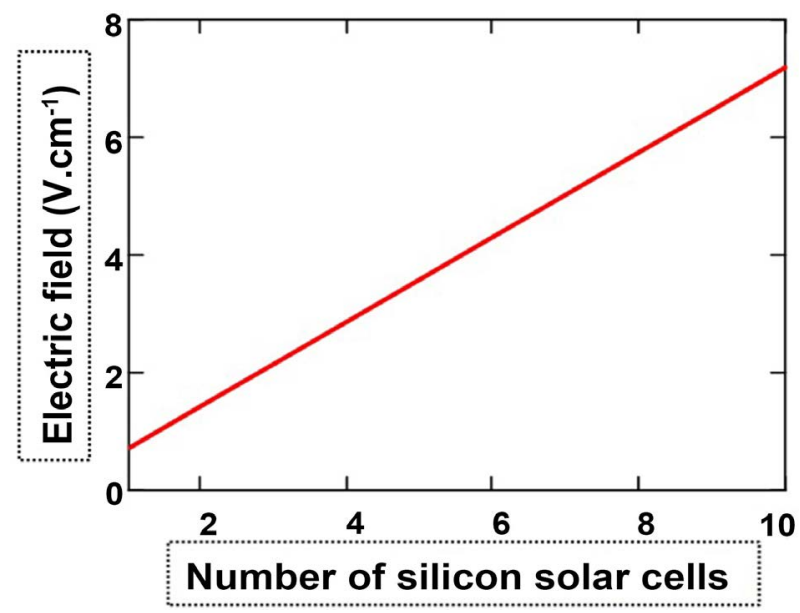

Figure 3. Electrical field in function of the silicon solar cells number. $\left(\lambda=0.70 \mu \mathrm{m}, S_{b}=10^{4} \mathrm{~cm} \cdot \mathrm{s}^{-1}, L_{n}=150 \mu \mathrm{m}, D_{n}=26\right.$ $\left.\mathrm{cm}^{2} \cdot \mathrm{s}^{-1}, \mu_{\mathrm{n}}=1000 \mathrm{~cm}^{2} \cdot \mathrm{V}^{-1} \cdot \mathrm{s}^{-1}\right)$.

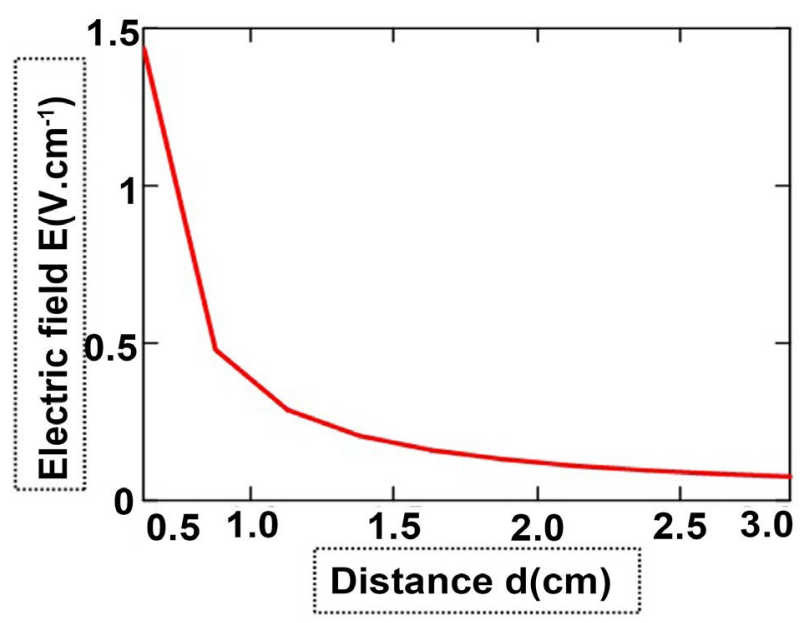

Figure 4. Electrical field in function of the distances between anode and cathode. $\left(\lambda=0.70 \mu \mathrm{m}, S_{b}=10^{4} \mathrm{~cm} \cdot \mathrm{s}^{-1}, L_{n}=150\right.$ $\left.\mu \mathrm{m}, D_{n}=26 \mathrm{~cm}^{2} \cdot \mathrm{s}^{-1}, \mu_{\mathrm{n}}=1000 \mathrm{~cm}^{2} \cdot \mathrm{V}^{-1} \cdot \mathrm{s}^{-1}, n=1\right)$.

The evolution of the electric field in function of the solar illumination wavelength has the solar spectrum characteristic because of the solar illumination atmospheric absorption. The short wavelength causes more storage of the generated electronic near the junction i.e. p side. Moreover, the electrical field is decreasing with the increase of wavelength. Hence, to simulate the electrical field effect on the silicon solar cells installed into influence area of this electrical field, one solar cell is chosen for the illumination wavelength of $0.70 \mu \mathrm{m}$ with the variation of the distances. The following subsection will present the influence of the electrical field on one silicon solar cell's electrical parameters in 1D approach.

\subsection{Influence of the Electrical Field on the Electric Parameters}

The electric parameters treated in this point concern the photocurrent, the photovoltage, the electric power and the conversion efficiency. The Figure 6 is the 


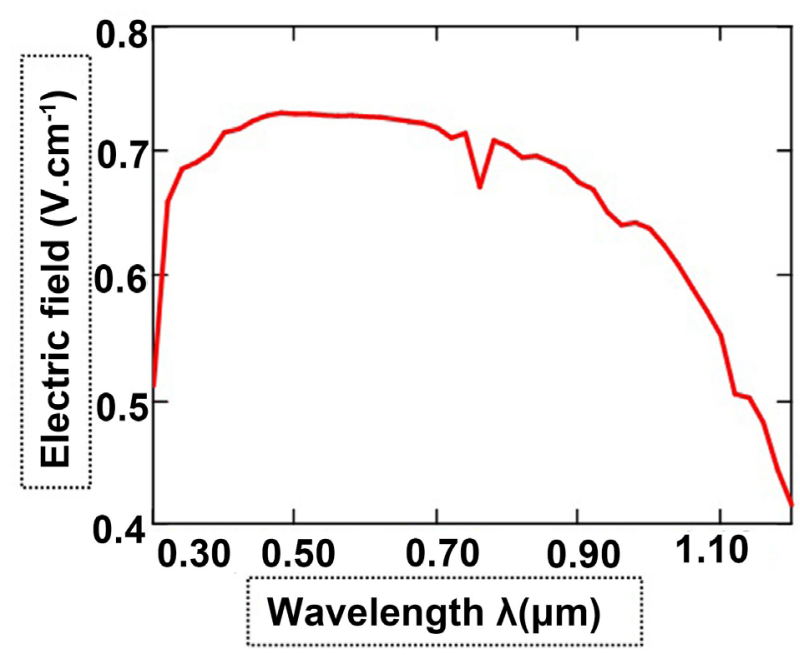

Figure 5. Electrical field in function of the wavelengths of the solar illumination. $\left(n=1, S_{b}=10^{4} \mathrm{~cm} \cdot \mathrm{s}^{-1}, L_{n}=150 \mu \mathrm{m}, D_{n}=\right.$ $\left.26 \mathrm{~cm}^{2} \cdot \mathrm{s}^{-1}, \mu_{\mathrm{n}}=1000 \mathrm{~cm}^{2} \cdot \mathrm{V}^{-1} \cdot \mathrm{s}^{-1}\right)$.

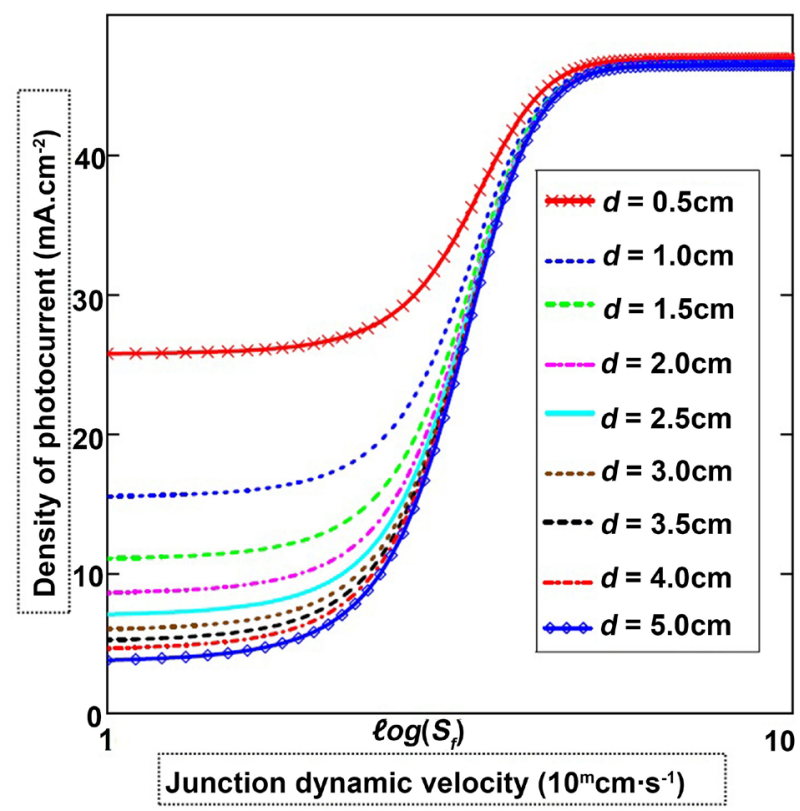

Figure 6. Photocurrent density in function of the dynamic junction velocity for different distances. $\left(\lambda=0.70 \mu \mathrm{m}, S_{b}=\right.$ $10^{4} \mathrm{~cm} \cdot \mathrm{s}^{-1}, L_{n}=150 \mu \mathrm{m}, D_{n}=26 \mathrm{~cm}^{2} \cdot \mathrm{s}^{-1}, \mu_{\mathrm{n}}=1000 \mathrm{~cm}^{2} \cdot \mathrm{V}^{-1} \cdot \mathrm{s}^{-1}$, $n=1)$.

graphic representation of the density of photocurrent in function of the dynamic velocity and the variation of the distances.

From low values of the junction dynamic velocity to high values of this velocity, the solar cell operating point is going from open circuit state to short circuit situation. It appears the increase of the photocurrent from open circuit to short circuit situation. For the intermediate level between open circuit and short circuit situations, the photocurrent presents an improvement. This state is the real 
operating point of the solar cell. The photocurrent at this state is improving also for the short distance i.e. for the high value of the electrical field. But the important value obtained at the open circuit state can cause the heating by Joule effect of the junction of the solar cell. It will be better to minimize this open circuit photocurrent which presents only the loss of the generated exceeding minority carriers at the junction. The photovoltage is represented on the Figure 7 in function of the junction dynamic velocity for different distances.

The photovoltage is greatest in the open circuit state. It decreases when the solar cell is operating in short circuit. The photovoltage is slightly insensitive to the electric field. But the values of the photovoltage is decreasing with the short distances between the both aluminum conductors. This reduction is the consequence of the crossing of the $\mathrm{p}-\mathrm{n}$ junction by the surplus minority carriers. We observe that the increase of the photocurrent is more important than the decrease of the photovoltage. The electric power is presented on the Figure 8 for different distances when the junction dynamic velocity varies.

For the short circuit situation, the solar cell does not deliver the electric power. But for the open circuit situation there is an electric power. This power increases for the short distances between the both aluminum conductors. The electric power in open circuit causes the heating of the junction $\mathrm{p}-\mathrm{n}$ of the solar cell by Joule effect. So, for this dispositive of improvement of the solar cell efficiency, the air free convection can be used to evacuate the heat coming from this open circuit electric power. Then, the maximum electric power $\left(P_{M P P}\right)$ is improving for the short distances. The Table 1 presents the $P_{M P P}$ collected from the Figure 8 and the conversion efficiency calculated using the Equation (11).

From $3.5 \mathrm{~cm}$ to $0.5 \mathrm{~cm}$ i.e. the electric field passes from $0.198 \mathrm{~V} \cdot \mathrm{cm}^{-1}$ to 1.387 $\mathrm{V} \cdot \mathrm{cm}^{-1}$, the electric power increases from $20.834 \mathrm{~mW} \cdot \mathrm{cm}^{-2}$ to $21.477 \mathrm{~mW} \cdot \mathrm{cm}^{-2}$ and the conversion efficiency increases from $24.5 \%$ to $25.2 \%$. In experimental study, E. Serafettin [13] finds in red color wavelength of a monochromatic illumination that the open circuit voltage decreases with the increase of the electric field but the short circuit current does not change. However, we observe an increase of $0.7 \%$ about conversion efficiency. This efficiency is better improved compared at efficiency of the silicon polycrystalline solar cell which does not influence by the electric field [7]. This increase can improve with the reduction of distance between the both aluminum conductors. It can also improve by the increase of the number of the solar cells used for the creation of the electrical field and choosing the good angle between internal and external electric fields. Moreover, the short distances values bring the operating point of the solar cell in vicinity of the open circuit state.

\section{Conclusions}

A modeling of the integration of the production source of the electrical field in the silicon solar cell or solar module system under monochromatic illumination was studied. The study of the influence of the electrical field on the polycrystalline silicon solar cell has showed an improvement of the conversion efficiency. 


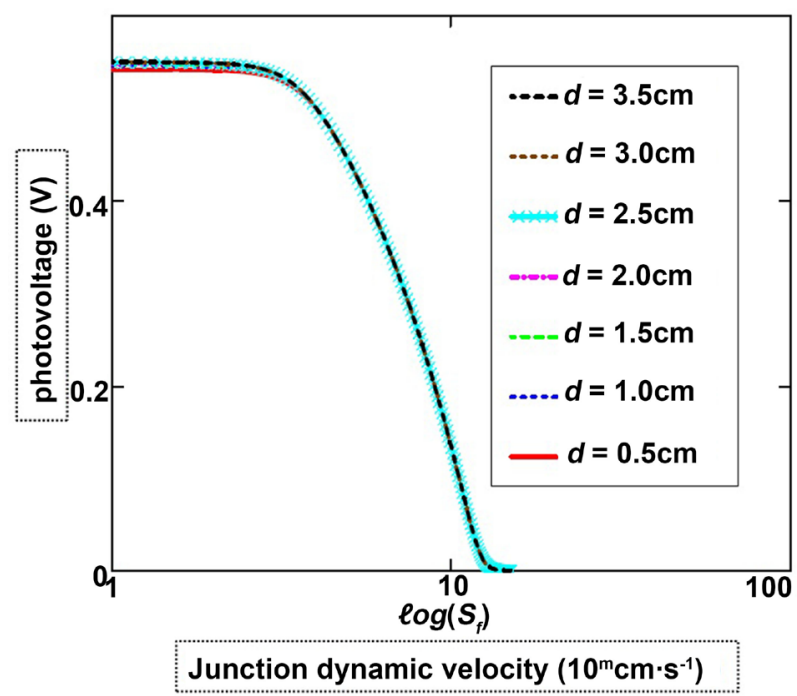

Figure 7. Photovoltage in function of the dynamic junction velocity for different distances. $\left(\lambda=0.70 \mu \mathrm{m}, S_{b}=10^{4} \mathrm{~cm} \cdot \mathrm{s}^{-1}, L_{n}\right.$ $\left.=150 \mu \mathrm{m}, D_{n}=26 \mathrm{~cm}^{2} \cdot \mathrm{s}^{-1}, \mu_{\mathrm{n}}=1000 \mathrm{~cm}^{2} \cdot \mathrm{V}^{-1} \cdot \mathrm{s}^{-1}, n=1\right)$.

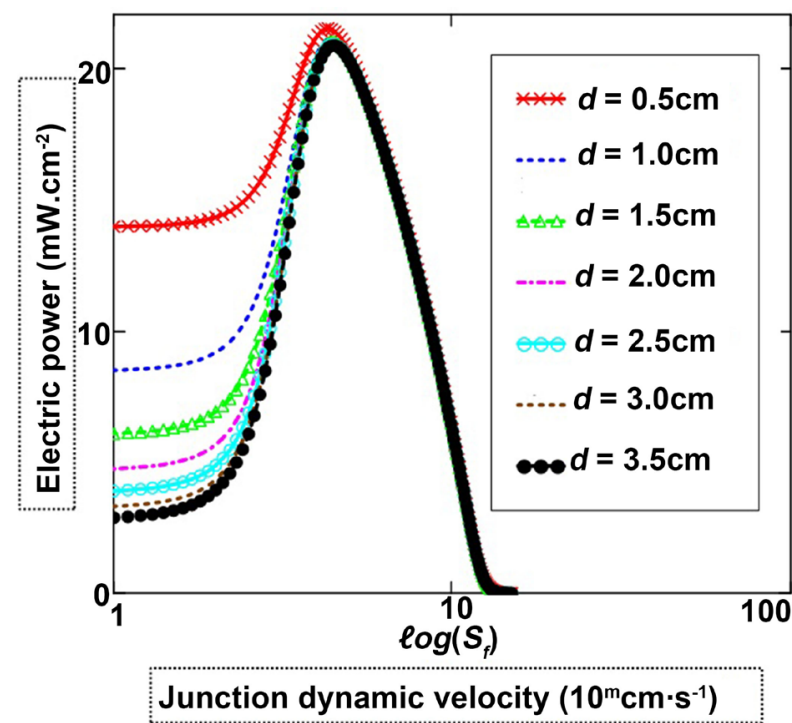

Figure 8. Electric power in function of the dynamic junction velocity for different distances. $\left(\lambda=0.70 \mu \mathrm{m}, S_{b}=10^{4} \mathrm{~cm} \cdot \mathrm{s}^{-1}, L_{n}\right.$ $\left.=150 \mu \mathrm{m}, D_{n}=26 \mathrm{~cm}^{2} \cdot \mathrm{s}^{-1}, \mu_{\mathrm{n}}=1000 \mathrm{~cm}^{2} \cdot \mathrm{V}^{-1} \cdot \mathrm{s}^{-1}, n=1\right)$.

A planar capacitor has been created. It uses two aluminum conductors connected to a first solar cell which provides the open circuit photovoltage. This system gives a uniform electric field. The second solar studied under the influence of this uniform electrical field presents an improvement of its performances. The improvement of the second silicon solar cell conversion efficiency is caused by the electrical field created between the both aluminum conductors. The main consequence of this increase of the conversion efficiency by using the open circuit photovoltage is the reduction of the semi-conductor matter for the solar cells manufacturing. Hence, this technical way can allow the fabrication of 
Table 1. Conversion efficiency for different dynamic junction velocities and for different distances. $\left(\lambda=0.70 \mu \mathrm{m}, S_{b}=10^{4} \mathrm{~cm} \cdot \mathrm{s}^{-1}, L_{n}=150 \mu \mathrm{m}, D_{n}=26 \mathrm{~cm}^{2} \cdot \mathrm{s}^{-1}, \mu_{\mathrm{n}}=1000\right.$ $\left.\mathrm{cm}^{2} \cdot \mathrm{V}^{-1} \cdot \mathrm{s}^{-1}, n=1\right)$.

\begin{tabular}{cccc}
\hline$d(\mathrm{~cm})$ & $P_{M P P}\left(\mathrm{~mW} \cdot \mathrm{cm}^{-2}\right)$ & $S_{f}\left(10^{\mathrm{m}} \mathrm{cm} \cdot \mathrm{s}^{-1}\right)$ & $\eta(\%)$ \\
\hline 3.5 & 20.834 & 4.5 & 24.5 \\
3 & 20.851 & 4.5 & 24.5 \\
2.5 & 20.878 & 4.4 & 24.5 \\
2 & 20.919 & 4.4 & 24.6 \\
1.5 & 20.987 & 4.4 & 24.7 \\
1 & 21.114 & 4.4 & 24.8 \\
0.5 & 21.477 & 4.3 & 25.2 \\
\hline
\end{tabular}

the low-cost solar cells and solar modules. That is a contribution for developing countries accessibility to the energy and a reduction of the global climate change.

\section{Conflicts of Interest}

The authors declare no conflicts of interest regarding the publication of this paper.

\section{References}

[1] Michaud, J.G. (2005) La fabuleuse histoire de l'nergie solaire. INCA Productions, Californie, E-U.

[2] Siert, P. (1979) Nouvelles techniques de réalisation de photopiles au silicium. Revue de Physique Appliquee, 14, 169-192. https://doi.org/10.1051/rphysap:01979001401016900

[3] Green, A.M., Yoshihiro, H., Hishikawa, Y., Warta, W., Ewan, D.D., Dean, H.L., Jochen, H.E. and Anita, W.Y.H. (2017) Solar Cell Efficiency Tables (Version 50). Progress in Photovoltaics. Research and Applications, 25, 668-676. https://doi.org/10.1002/pip.2909

[4] Green, A.M., Yoshihiro, H., Hishikawa, Y., Warta, W., Ewan, D.D., Dean, H.L., Jochen, H.E. and Anita, W.Y.H. (2018) Solar Cell Efficiency Tables (Version 51). Progress in Photovoltaics. Research and Applications, 26, 3-12. https://doi.org/10.1002/pip.2978

[5] Priyanka, S. and Ravindra, N.M. (2012) Temperature Dependence of Solar Cell Performance-An Analysis. Solar Energy Materials \& Solar Cells, 101, 36-45. https://doi.org/10.1016/j.solmat.2012.02.019

[6] Moliton, A. (2009) Electronique et photo - électronique des matriaux et composants 2: Photo - electronique et composants. Hermes Science.

[7] Mathieu, H. and Fanet, H. (2009) Physique des semiconducteurs et des composants électroniques. Dunod, 6e Edition.

[8] Zerbo, I., Zoungrana, M., Ouedraogo, A., Korgo, B., Zouma, B. and Bathiebo, D.J. (2014) Influence of Electromagnetic Waves Produced by an Amplitude Modulation Radio Antenna on the Electric Power Delivered by a Silicon Solar Cell. Global Journal of Pure and Applied Sciences, 20, 139-148. 
[9] Ouedraogo, A., Barandja, V.D.B., Zerbo, I., Zoungran, M., Ramde, E.W. and Bathiebo, D.J. (2017) A Theoretical Study of Radio Wave Attenuation through a Polycrystalline Silicon Solar Cell. Turkish Journal of Physics, 41, 314-325. https://doi.org/10.3906/fiz-1703-16

[10] Zerbo, I., Saria, M., Zoungrana, M., Ouedraogo, A. and Bathiebo, D.J. (2017) Effect of Incidence Angle Varying from $0 \mathrm{Rad}$ to $\pi / 2 \mathrm{Rad}$ and Intensity of Radio Waves on the Performance of a Silicon Solar Cell. Advances in Science and Technology Research Journal, 11, 68-75. https://doi.org/10.12913/22998624/80090

[11] Zerbo, I., Zoungrana, M., Sourabie, I., Ouedraogo, A., Zouma, B. and Bathiebo, D.J. (2015) External Magnetic Field Effect on Bifacial Silicon Solar Cell's Electric Power and Conversion Efficiency. Turkish Journal of Physics, 39, 288-294. https://doi.org/10.3906/fiz-1505-10

[12] Zoungrana, M., Dieng, B., Lemrabolt, O.H., Toure, F., Ould El Moujtaba, M.A., Sow, M.L. and Sissoko, G. (2012) External Electric Field Influence on Charge Carriers and Electrical Parameters of Polycrystalline Silicon Solar Cell. Research Journal of Applied Sciences, Engineering and Technology, 4, 2967-2972.

[13] Serafettin, E. (2008) Comparing the Behaviours of Some Typical Solar Cells under External Effects. Teknoloji, 11, 233-237.

[14] Serafettin, E., Mustafa, A., Gazi, K.E. and Veli, C. (2006) The Behaviour of a Typical Singlerystal Si Solar Cell under High Intensity of Electric Field. Solar Energy Materials \& Solar Cells, 90, 582-587. https://doi.org/10.1016/j.solmat.2005.04.038

[15] ICNIRP (1998) ICNIRP Guidelines for Limiting Exposure to Time-Varying Electric, Magnetic and Electromagnetic Fields (up to $300 \mathrm{GHz}$ ). Health Physics, 74, 494-522.

[16] Madougou, S., Made, F., Boukary, M.S. and Sissoko, G. (2007) I - V Characteristics for Bifacial Silicon Solar Cell Studied under a Magnetic Field. Advanced Materials Research, 18-19, 333-312.

[17] Betser, Y., Ritter, D., Bahir, G., Cohen, S. and Sperling, J. (1995) Measurement of the Minority Carrier Mobility in the Base of Heterojunction Bipolar Transistors using a Magnetotransport Method. Applied Physics Letters, 67, 1883. https://doi.org/10.1063/1.114364

[18] Zerbo, I., Zoungrana, M., Sere, A.D., Ouedraogo, F., Sam, R., Zouma, B. and Zougmore, F. (2011) Influence d'une onde électromagnetique sur une photopile au silicium sous éclairement multispectral en regime statique. Revue des Energies Renouvelables, 14, 517-532.

[19] Shockley, W. and Read Jr., W.T. (1952) Statistics of the Recombinations of Holes and Electrons. Physical Review, 87, 835-842.

https://doi.org/10.1103/PhysRev.87.835

[20] Green, A.M. (2008) Self-Consistent Optical Parameters of Intrinsic Silicon at $300 \mathrm{~K}$ Including Temperature Coefficients. Solar Energy Materials \& Solar Cells. https://doi.org/10.1016/j.solmat.2008.06.009

[21] Zerbo, I., Zoungrana, M., Sere, A.D. and Zougmore, F. (2012) Silicon Solar Cell Under Electromagnetic Wave in Steady State: Effect of the Telecommunication Source's Power of Radiation. IOP Conference Series. Materials Science and Engineering, 29, 12-19.

[22] Zerbo, I., Zoungrana, M., Ouedraogo, A. and Bathiebo, D.J. (2017) Effect of Junction Quality on the Performance of a Silicon Solar Cell. Journal of Fundamental and Applied Sciences, 9, 1012-1026. https://doi.org/10.4314/jfas.v9i2.26

[23] Sow, O., Zerbo, I., Mbodji, S., Ngom, M.I., Diouf, M.S. and Sissoko, G. (2012) Sili- 
con Solar Cell under Electromagnetic Waves in Steady State: Electrical Parameters Determination Using the I-V and P-V Characteristics. International Journal of Science, Environment and Technology, 1, 230-246. 